Article

\title{
Preparation of Magnetic Nanoparticles via a Chemically Induced Transition: Role of Treating Solution's Temperature
}

\author{
Ting Zhang ${ }^{1}$, Xiangshen Meng ${ }^{1}$, Zhenghong He ${ }^{1}$, Yueqiang Lin ${ }^{1}$, Xiaodong Liu ${ }^{1}$, Decai Li ${ }^{2}$, \\ Jian $\mathrm{Li}^{1, *}$ (1) and Xiaoyan Qiu ${ }^{1, *}$ \\ 1 School of Physical Science and Technology, Southwest University, Chongqing 400715, China; \\ zhangting07@email.swu.edu.cn (T.Z.); 15552267851@163.com (X.M.); hezhenho@swu.edu.cn (Z.H.); \\ linyq@swu.edu.cn (Y.L.); liuzm@swu.edu.cn (X.L.) \\ 2 State Key Laboratory of Tribology, Tsinghua University, Beijing 100084, China; lidecai@tsinghua.edu.cn \\ * Correspondence: aizhong@swu.edu.cn (J.L.); qxy2001@swu.edu.cn (X.Q.)
}

Received: 14 June 2017; Accepted: 3 August 2017; Published: 12 August 2017

\begin{abstract}
Using $\mathrm{FeOOH} / \mathrm{Mg}(\mathrm{OH})_{2}$ as precursor and $\mathrm{FeCl}_{2}$ as the treating solution, we prepared $\gamma-\mathrm{Fe}_{2} \mathrm{O}_{3}$ based nanoparticles. The $\mathrm{FeCl}_{2}$ treating solution catalyzes the chemical reactions, dismutation and oxygenation, leading to the formation of products $\mathrm{FeCl}_{3}$ and $\mathrm{Fe}_{2} \mathrm{O}_{3}$, respectively. The treating solution $\left(\mathrm{FeCl}_{2}\right)$ accelerates dehydration of the $\mathrm{FeOOH}$ compound in the precursor and transforms it into the initial seed crystallite $\gamma-\mathrm{Fe}_{2} \mathrm{O}_{3}$. $\mathrm{Fe}_{2} \mathrm{O}_{3}$ grows epitaxially on the initial seed crystallite $\gamma-\mathrm{Fe}_{2} \mathrm{O}_{3}$. The epitaxial layer has a magnetically silent surface, which does not have any magnetization contribution toward the breaking of crystal symmetry. $\mathrm{FeCl}_{3}$ would be absorbed to form the $\mathrm{FeCl}_{3} \cdot 6 \mathrm{H}_{2} \mathrm{O}$ surface layer outside the particles to form $\gamma-\mathrm{Fe}_{2} \mathrm{O}_{3} / \mathrm{FeCl}_{3} \cdot 6 \mathrm{H}_{2} \mathrm{O}$ nanoparticles. When the treating solution's temperature is below $70{ }^{\circ} \mathrm{C}$, the dehydration reaction of $\mathrm{FeOOH}$ is incomplete and the as-prepared samples are a mixture of both $\mathrm{FeOOH}$ and $\gamma-\mathrm{Fe}_{2} \mathrm{O}_{3} / \mathrm{FeCl}_{3} \cdot 6 \mathrm{H}_{2} \mathrm{O}$ nanoparticles. As the treating solution's temperature increases from 70 to $90^{\circ} \mathrm{C}$, the contents of both $\mathrm{FeCl}_{3} \cdot 6 \mathrm{H}_{2} \mathrm{O}$ and the epitaxial $\mathrm{Fe}_{2} \mathrm{O}_{3}$ increased in totality.
\end{abstract}

Keywords: $\gamma-\mathrm{Fe}_{2} \mathrm{O}_{3}$ nanoparticle; $\mathrm{FeCl}_{2}$ solution; temperature; magnetization

\section{Introduction}

Nanotechnology involves the study of matter whose dimensions approximately range between 1 and $100 \mathrm{~nm}$ [1]. Nanoparticles are typically defined as tiny solids, whose dimensions do not exceed $100 \mathrm{~nm}$ in all the three directions [2]. Magnetic nanoparticles have attracted a lot of interest in the community of researchers, because these tiny particles are extremely useful models for understanding the fundamental aspects of magnetic ordering phenomena in magnetic materials with small dimensions. The findings of these research studies can be used to develop novel technological applications [3-5]. In most studies of magnetic nanoparticles, scientists have tried to develop novel synthesis methods [2]. Liquid phase synthesis is one of the most common methods to produce inorganic nanoparticles. Many oxide nanoparticles, including ferrite particles, can be synthesized by co-precipitation. The chemical reactions involved in the synthesis of oxide nanoparticles can be classified into two categories: (i) oxide nanoparticles produced directly and (ii) production of a precursor that is then subjected to further processing, such as drying, calcination, etc. [6]. During the chemical reaction, a new phase is formed that is later subjected to further processing, such as calcination or annealing.

Presently, $\gamma-\mathrm{Fe}_{2} \mathrm{O}_{3}$ (maghemite) particles are one of the commonly used ferric oxide particles for their simple synthesis procedures and chemical stability [7]. Maghemite exhibits ferrimagnetic behavior at temperatures lower than $1000 \mathrm{~K}$. Furthermore, it is found in corrosion products, but 
also in several useful compounds, including proteins [8]. It has many industrial applications: as a drug delivery agent; in nuclear magnetic resonance imaging; in magnetic data storage applications; etc. [7-9]. Previous studies have described many novel methods for the preparation of $\gamma-\mathrm{Fe}_{2} \mathrm{O}_{3}$ magnetic nanoparticles, including co-precipitation, gas-phase reaction, direct thermal decomposition, thermal decomposition/oxidation, sonochemical synthesis, microemulsion reaction, hydrothermal synthesis, vaporization-condensation, and sol-gel approach [10-18]. In general, the preparation of $\gamma-\mathrm{Fe}_{2} \mathrm{O}_{3}$ by $\mathrm{FeOOH}$ transformation is a complex process $[19,20]$ that can be summarized as follows:

$$
\alpha(\gamma) \mathrm{FeOOH} \stackrel{\text { dehydration }}{\longrightarrow} \alpha(\gamma)-\mathrm{Fe}_{2} \mathrm{O}_{3} \stackrel{\text { reduction }}{\longrightarrow} \mathrm{Fe}_{3} \mathrm{O}_{4} \stackrel{\text { oxidation }}{\longrightarrow} \gamma-\mathrm{Fe}_{2} \mathrm{O}_{3}
$$

We have found a new route to synthesize $\gamma-\mathrm{Fe}_{2} \mathrm{O}_{3}$ magnetic nanoparticles. In this method, we synthesize the precursor $\mathrm{FeOOH} / \mathrm{Mg}(\mathrm{OH})_{2}$ by conducting a chemical co-precipitation method. The resultant hydroxide precursor $\mathrm{FeOOH} / \mathrm{Mg}(\mathrm{OH})_{2}$ is subsequently treated in the liquid phase with $\mathrm{FeCl}_{2}$ solution [21]. During the treatment, $\mathrm{Mg}(\mathrm{OH})_{2}$ compound dissolves and the $\mathrm{FeOOH}$ undergoes dehydration and transforms into $\gamma-\mathrm{Fe}_{2} \mathrm{O}_{3}$ nanoparticles:

$$
\mathrm{FeOOH} / \mathrm{Mg}(\mathrm{OH})_{2} \underset{\text { inFecl }_{2} \text { solution }}{\longrightarrow} \gamma-\mathrm{Fe}_{2} \mathrm{O}_{3}+\mathrm{H}_{2} \mathrm{O}+\mathrm{Mg}^{2+}+\mathrm{OH}^{-}
$$

This method is known as chemically induced transition (CIT) [22,23]. Under boiling conditions, we could synthesize $\gamma-\mathrm{Fe}_{2} \mathrm{O}_{3}$ nanoparticles coated by $\mathrm{FeCl}_{3} \cdot 6 \mathrm{H}_{2} \mathrm{O}$ by ensuring that the concentration of the $\mathrm{FeCl}_{2}$ solution was in the range of $0.06-0.25 \mathrm{M}$ [23]. In this experimental study, we adjust the temperature of the treating solution and investigate whether magnetization is dependent on the temperature, and the relevance between magnetization and components.

\section{Experimental}

\subsection{Preparation Using Chemicals}

From China National Medicines Corporation Ltd. (Shanghai, China), we purchased the following analytical reagent (AR) grade chemicals: $\mathrm{FeCl}_{3} \cdot 6 \mathrm{H}_{2} \mathrm{O}, \mathrm{Mg}(\mathrm{OH})_{2} \cdot 6 \mathrm{H}_{2} \mathrm{O}, \mathrm{NaOH}, \mathrm{FeCl}_{2} \cdot 4 \mathrm{H}_{2} \mathrm{O}$ and acetone. Since these reagents were of AR quality, we used them without performing further purification. We used only distilled water for performing the preparations of solutions in the experiment.

While performing this CIT method, we categorically divided the preparation process of nanoparticles into two steps: (i) we carried out the well-known method of co-precipitation to synthesize a precursor based on $\mathrm{FeOOH}$; the precursor was wrapped with $\mathrm{Mg}(\mathrm{OH})_{2}$. The synthesis of this precursor has been described in detail elsewhere [21]; (ii) we added $5 \mathrm{~g}$ of the dried precursor to $400 \mathrm{~mL}$ of $0.25 \mathrm{M} \mathrm{FeCl}_{2}$ solution. The $\mathrm{pH}$ of resultant solution was about 6 . Then, the resultant solution was heated to a certain temperature, and then it was refluxed for $30 \mathrm{~min}$ in air. After completing the process of heating, we were able to obtain nanoparticles gradually in the form of a precipitate. Finally, we washed the precipitate with acetone and air-dried it in the laboratory. We obtained the samples (1)-(5) by adjusting the temperature of the treating solution to the following respective values: $40,60,70,80$, and $90^{\circ} \mathrm{C}$.

\subsection{Characterization}

For precursor and samples (1)-(5), we measured the curves of specific magnetization $(\sigma)$ against field strength $(\mathrm{H})$ using vibrating sample magnetometer (VSM) (HH-15, Nanjing University Instrument Plant, Nanjing, China). After obtaining the measured results of VSM, we performed transmission electron microscopy (TEM) (TEM-2100F, Tokyo, Japan) on all the samples; however, we record particle morphologies only in the following typical sample (1) (treated solution temperature: $40^{\circ} \mathrm{C}$ ), sample (3) (treated solution temperature: $70{ }^{\circ} \mathrm{C}$ ), and sample (5) (treated solution temperature: $90{ }^{\circ} \mathrm{C}$ ), according to the results measured by VSM. Then, we analyzed the crystal structure of samples by 
X-ray diffraction (XRD) (D/Max-Rc, Rigaku, Tokyo, Japan). We analyzed the bulk chemical species by performing energy disperse $\mathrm{X}$-ray spectroscopy (EDS) in a scanning electron microscopy (SEM) (Quanta-200, FEI, Hillsboro, OR, USA). Finally, we analyzed surface chemical compositions of samples by performing X-ray photoelectron spectroscopy (XPS) (ESCALAB 250 xi, Thermo Fisher Scientific, Waltham, MA, USA).

\section{Results}

Figure 1 illustrates the curves representing the plot of $\sigma$ against $\mathrm{H}$ for various samples. The precursor was paramagnetic. In contrast, the as-prepared samples exhibited ferromagnetic transition because they were treated with $\mathrm{FeCl}_{2}$ solution. Furthermore, the specific magnetization of samples varied non-monotonically with an increase in the temperature of the treating solution: the magnetization $(\sigma)$ values increased drastically as the temperature of treating solution $\left(\mathrm{FeCl}_{2}\right)$ was increased from 40 to $70^{\circ} \mathrm{C}$, but then $\sigma$ values of samples decreased slightly with a further increase in temperature from $70{ }^{\circ} \mathrm{C}$ to $90^{\circ} \mathrm{C}$ of the treated solution. The specific saturation magnetization $\left(\sigma_{\mathrm{s}}\right)$ of the as-prepared samples was obtained from the plot of $\sigma$ versus $1 / \mathrm{H}$ at high field strength [24]. For samples (1)-(5), the $\sigma_{\mathrm{s}}$ values are $42.96,59.33,70.51,68.18$, and $66.61 \mathrm{~A} \cdot \mathrm{m}^{2} / \mathrm{kg}$, respectively.

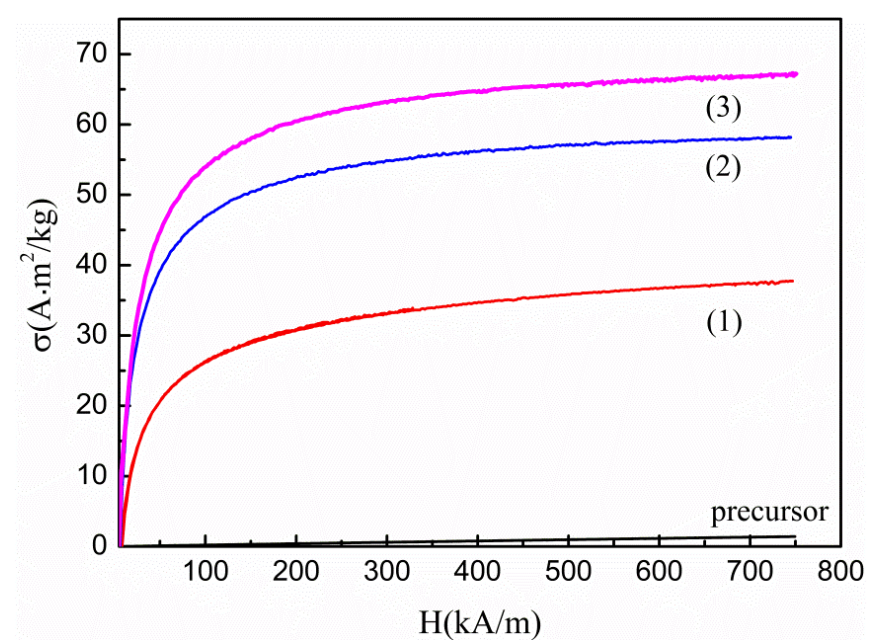

(a)

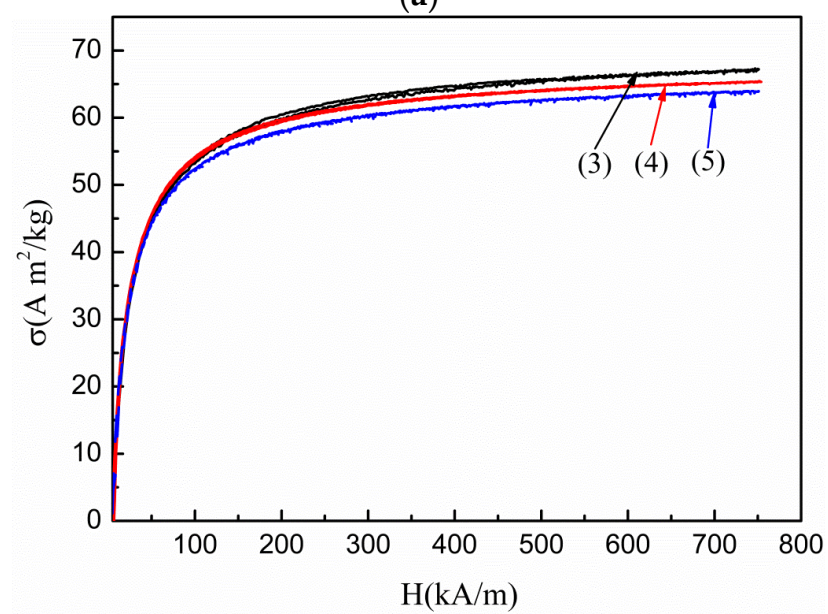

(b)

Figure 1. Specific magnetization curves of the precursor and as-prepared samples (1)-(3) (a), and as-prepared samples (3)-(5) (b). 
By performing TEM on all the samples, we noted the following observations: the samples (1), (3), and (5) are mostly spherical nanoparticles, with sizes ranging from 2 to $30 \mathrm{~nm}$. Figure 2 illustrates TEM images of the samples. In the case of Sample (1), TEM images clearly depict a small mixture (refer arrow A) and large (refer arrow B) particles. We performed statistical analysis of the results observed for samples (3) and (5) [25]. The histograms of the particle size are illustrated as the insets in Figure 2. Based on the statistical analysis, we inferred the particle size exhibited a log-normal form of distribution. Table 1 presents the median diameter, that is, the most probable value of the particle size $\mathrm{d}_{\mathrm{g}}$, and the standard deviation $\ln \sigma_{\mathrm{g}}$. High resolution TEM measurements have been performed in some of the samples (see inset in Figure 2), confirming that the nanoparticles are crystallines.
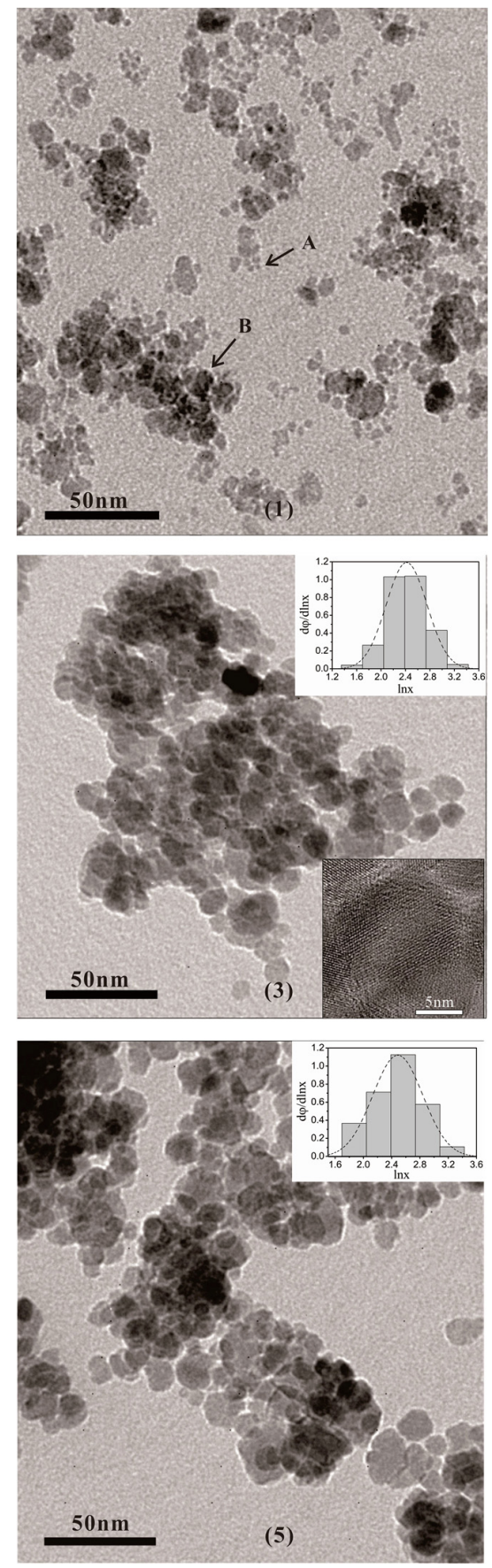

Figure 2. Typical TEM images for samples (1), (3), and (5). The insets are the histograms of the particle sizes for samples (3) and (5), and a High resolution TEM (HRTEM) image for sample (3). 
Table 1. Median size $\left(d_{g}\right)$, standard deviation $\left(\ln \sigma_{\mathrm{g}}\right)$ based on the TEM results, and grain size $\left(\mathrm{d}_{\mathrm{c}}\right)$ based on the XRD results for samples (3) and (5).

\begin{tabular}{cccc}
\hline Samples & $d_{g}(\mathbf{n m})$ & $\ln \sigma_{\mathbf{g}}$ & $\mathbf{d}_{\mathbf{c}}(\mathbf{n m})$ \\
\hline$(3)$ & 11.2 & 0.3 & 9.0 \\
$(5)$ & 12.0 & 0.3 & 9.0 \\
\hline
\end{tabular}

As shown in Figure 3, XRD patterns reveal that the samples (1), (3), and (5) predominantly contained maghemite $\left(\gamma-\mathrm{Fe}_{2} \mathrm{O}_{3}\right.$; JCPDS file $\left.39-1346\right)$ with traces of hydromolysite $\left(\mathrm{FeCl}_{3} \cdot 6 \mathrm{H}_{2} \mathrm{O}\right.$; JCPDS file 33-0645). In addition, sample (1) may contain some crystals of iron oxide hydroxide (FeOOH; JCPDS file 13-0157), whose diffraction peak in (211) plane $(2 \theta=35.264)$ overlapped with the diffraction peak of $\gamma-\mathrm{Fe}_{2} \mathrm{O}_{3}$ in (311) plane $(2 \theta=35.630)$. This phenomenon is attributed to the broadening of diffraction peaks. For samples (3) and (5), we used Scherrer's formula to estimate the most probable grain size $\left(d_{c}\right)$ from the half-maximum width of (311) diffraction peak $(\beta)[26,27]$. The expression of Scherrer's formula is as follows: $d_{c}=k \lambda / \beta \cos \theta$, where $k$ is the coefficient and equals to 0.89 [28], $\lambda$ is the wavelength ( $\mathrm{Cu} \mathrm{K} \alpha$ wavelength is $0.1542 \mathrm{~nm})$, and $\theta$ is the Bragg diffraction angle of (311) plane. Table 1 presents $d_{c}$ values of samples (3) and (5). These values indicate that $d_{c}$ value is almost same for both the samples (3) and (5).

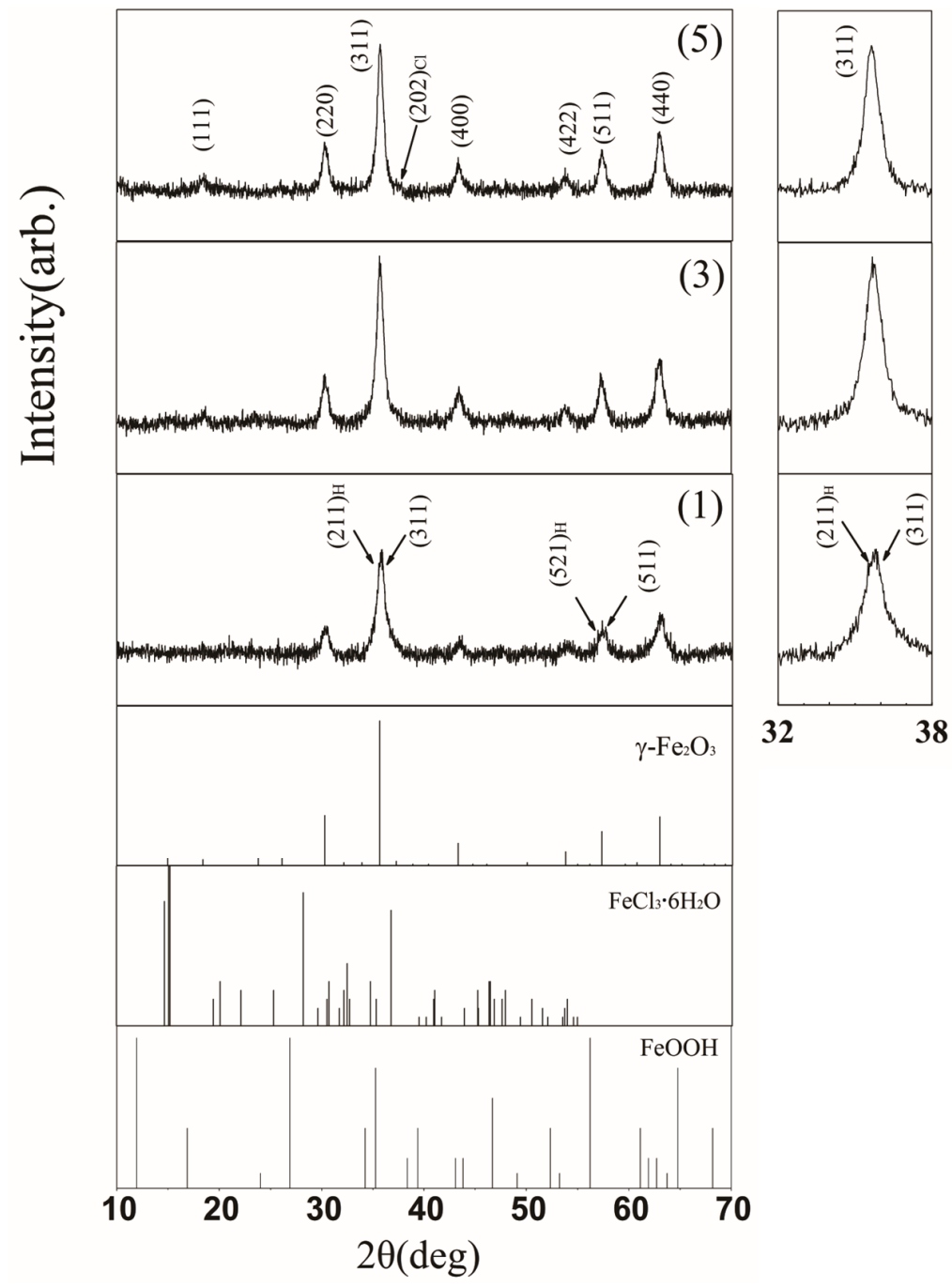

Figure 3. XRD spectra of samples (1), (3), and (5) with (hkl), (hkl) $\mathrm{Cl}$ and (hkl) $)_{\mathrm{Mg}}$ corresponding to $\gamma-\mathrm{Fe}_{2} \mathrm{O}_{3}, \mathrm{FeCl}_{3} \cdot 6 \mathrm{H}_{2} \mathrm{O}$ and $\mathrm{FeOOH}$ phases, respectively. 
By performing energy-dispersive $X$-ray spectroscopy (EDS), we found that all the three samples contained $\mathrm{O}, \mathrm{Fe}$, and $\mathrm{Cl}$, but not $\mathrm{Mg}$ and $\mathrm{Na}$. For quantitative analysis, many zones were probed to average the content of each element. Figure 4 illustrates images of typical EDS spectra. Table 2 summarizes the quantitative results of this experiment.

Table 2. Atomic percentages $\left(\mathrm{a}_{i}\right)$ of $\mathrm{O}, \mathrm{Fe}$, and $\mathrm{Cl}$ obtained by EDS and XPS measurements in samples (1), (3), and (5).

\begin{tabular}{ccccccc}
\hline \multirow{2}{*}{ Samples } & \multicolumn{3}{c}{ EDS } & \multicolumn{3}{c}{ XPS } \\
\cline { 2 - 7 } & $\mathbf{O}$ & $\mathbf{F e}$ & $\mathbf{C l}$ & $\mathbf{O}$ & $\mathbf{F e}$ & $\mathbf{C l}$ \\
\hline$(1)$ & 40.43 & 51.58 & 1.99 & 64.06 & 31.99 & 3.96 \\
$(3)$ & 45.16 & 52.56 & 2.28 & 64.15 & 35.98 & 3.87 \\
$(5)$ & 45.31 & 52.92 & 1.77 & 58.02 & 32.89 & 5.17 \\
\hline
\end{tabular}

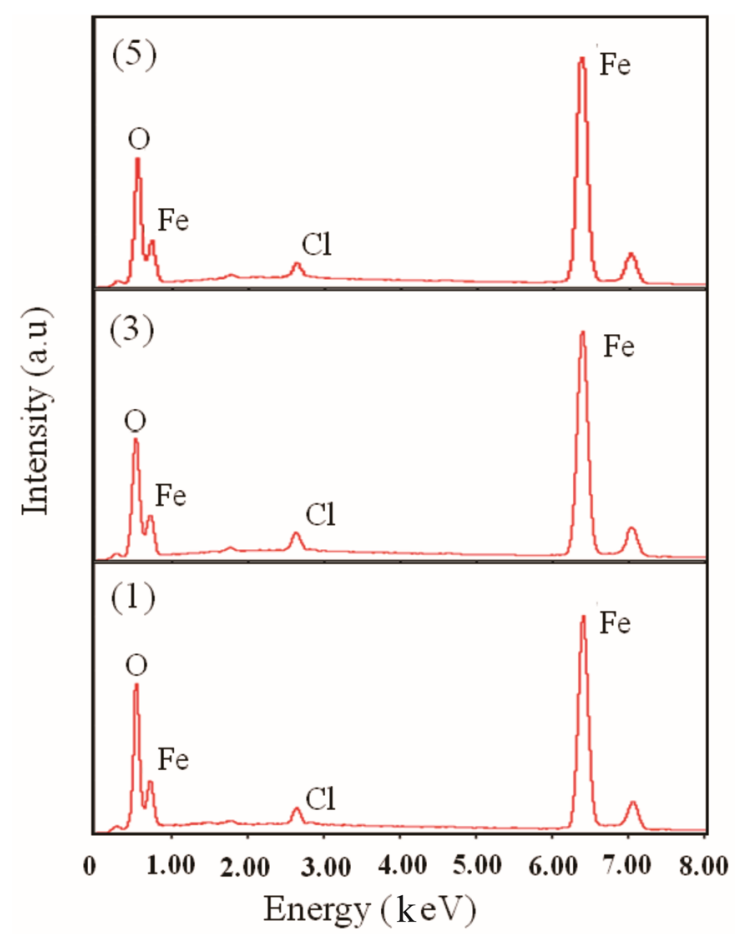

Figure 4. EDS spectra of samples (1), (3), and (5).

After comparing the results of samples analyzed by XRD and EDS techniques, we conclude that $\gamma-\mathrm{Fe}_{2} \mathrm{O}_{3}$ and $\mathrm{FeCl}_{3} \cdot 6 \mathrm{H}_{2} \mathrm{O}$ may be the primary constituents in samples (1), (3), and (5); however, an additional $\mathrm{FeOOH}$ compound may be present in sample (1). To examine the surface characteristics of particles, we performed an XPS analysis on the samples. The results of the XPS analysis indicate that the chemical species detected in each sample were the same as those detected by EDS. Table 2 presents a quantitative analysis of results. For sample (1), O1s spectra can be resolved into two peaks: P1 and P2 (See Figure 5a). The P1 peak corresponds to O1s line in samples (3) and (5), which approximately appears at $529.3 \mathrm{eV}$. Thus, the P1 peak's energy agreed with the binding energy of O1s in ferric oxide. The P2 peak appears at $530.66 \mathrm{eV}$, which is same as the binding energy of O1s in FeOOH. Furthermore, the Fe $2 p_{3 / 2}$ spectra for sample (1), (3), and (5) can be resolved into two peaks: P1 and P2. As shown in Figure $5 \mathrm{~b}$, peak $\mathrm{P} 1$ corresponds to $\mathrm{Fe} 2 \mathrm{p}_{3 / 2}$ line of $\mathrm{Fe}_{2} \mathrm{O}_{3}$, while $\mathrm{P} 2$ peak corresponds to that of $\mathrm{FeOOH}$ and /or $\mathrm{FeCl}_{3}$. Table 3 summarizes the results obtained by performing XPS analysis on the samples. Thus, based on the binding energy data, we conclude that $\gamma-\mathrm{Fe}_{2} \mathrm{O}_{3}, \mathrm{FeCl}_{3} \cdot 6 \mathrm{H}_{2} \mathrm{O}$ and $\mathrm{FeOOH}$ were present in sample (1), while $\gamma-\mathrm{Fe}_{2} \mathrm{O}_{3}$ and $\mathrm{FeCl}_{3} \cdot 6 \mathrm{H}_{2} \mathrm{O}$ were present in samples (3) and (5). 


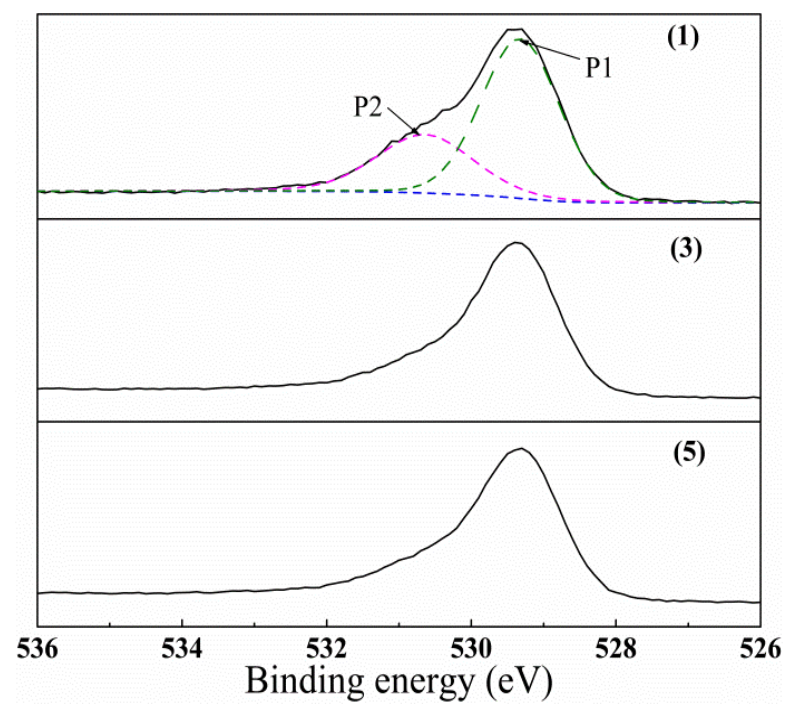

(a)

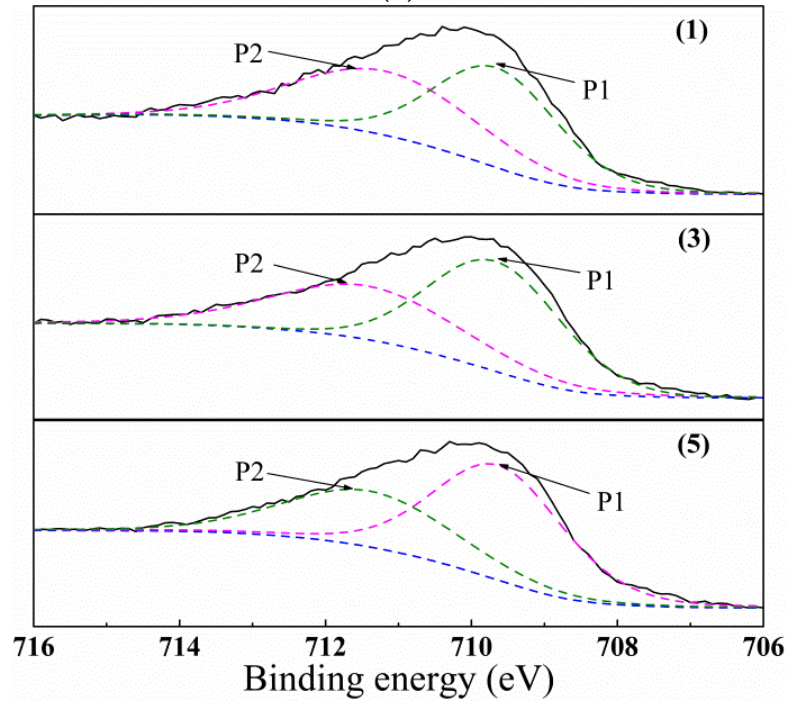

(b)

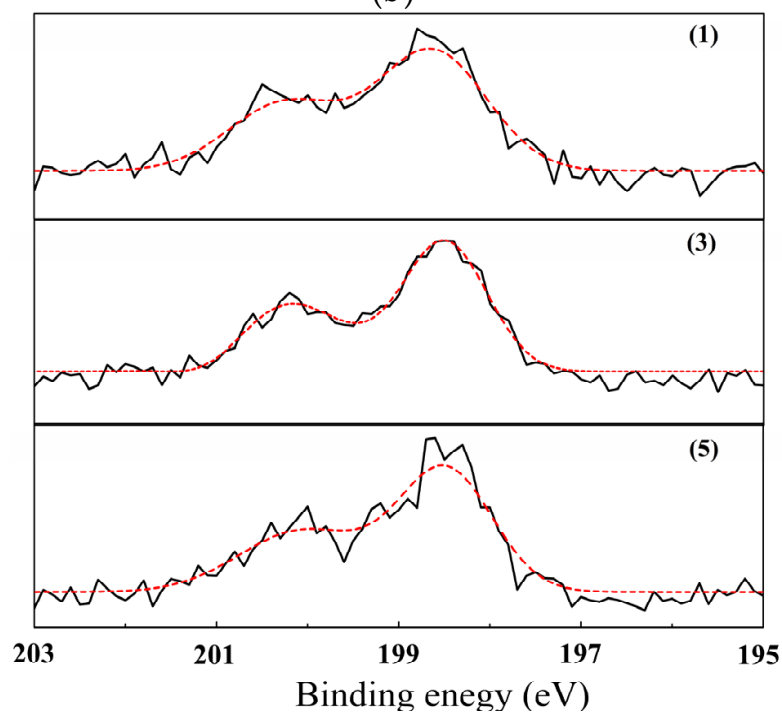

(c)

Figure 5. XPS spectra of samples (1), (3), and (5), representing $\mathrm{O}$ ls (a) Fe $2 \mathrm{p}_{3 / 2}$ (b) and $\mathrm{Cl} 2 \mathrm{p}$ (c) line regions. 
Table 3. Binding energies data from XPS (eV) for elements present in samples (1), (3), and (5).

\begin{tabular}{llllll}
\hline Samples & O ls & & Fe 2 $p_{3 / 2}$ & & Cl 2 $\mathbf{p}_{\mathbf{3} / \mathbf{2}}$ \\
\hline$(1)$ & $529.32(\mathrm{P} 1)$ & $530.46(\mathrm{P} 2)$ & $709.66(\mathrm{P} 1)$ & $711.19(\mathrm{P} 2)$ & 198.7 \\
$(3)$ & 529.38 & & $709.67(\mathrm{P} 1)$ & $711.44(\mathrm{P} 2)$ & 198.5 \\
$(5)$ & 529.36 & & $709.63(\mathrm{P} 1)$ & $711.40(\mathrm{P} 2)$ & 198.5 \\
$\mathrm{Fe}_{2} \mathrm{O}_{3}$ & 529.5 & & 709.9 & & \\
$\mathrm{FeCl}_{3}$ & & & & 711.3 & 199.0 \\
$\mathrm{FeOOH}$ & & 530.1 & & 711.5 & \\
\hline
\end{tabular}

Note: Standard data from the NIST online database for XPS at http:/ / www.nist.gov.

\section{Discussion}

Based on the experimental results, it is showed that the magnetization of as-prepared samples varied non-monotonically with an increase in the temperature of treated solution. Combining the results from XRD and XPS, we conclude there could be $\gamma-\mathrm{Fe}_{2} \mathrm{O}_{3}$ and $\mathrm{FeCl}_{3} \cdot 6 \mathrm{H}_{2} \mathrm{O}$ phases in all samples and an addition $\mathrm{FeOOH}$ phase in sample (1), which is in agreement with our previous work [21]. In addition, it is noticed that the ferrite-like spinel structure, $\gamma-\mathrm{Fe}_{2} \mathrm{O}_{3}$ and $\mathrm{Fe}_{3} \mathrm{O}_{4}$, is difficult to discriminate by XRD due to peak broadening [29] or by XPS because the data are very close (the binding energy of $\mathrm{Fe} 2 \mathrm{p}_{3 / 2}$ in $\mathrm{Fe}_{3} \mathrm{O}_{4}$ is $710.8 \mathrm{eV}$ ). However, $\mathrm{Fe}_{3} \mathrm{O}_{4}$ is not stable and is sensitive to oxidation [9]. It was found that $\mathrm{Fe}_{3} \mathrm{O}_{4}$ nanocrystallites transformed into $\gamma-\mathrm{Fe}_{2} \mathrm{O}_{3}$ nanocrystallites using $\mathrm{Fe}\left(\mathrm{NO}_{3}\right)_{3}$ solution treatment [30]. Therefore, it is judged that the magnetic compound for the as-prepared samples is $\gamma-\mathrm{Fe}_{2} \mathrm{O}_{3}$, rather than $\mathrm{Fe}_{3} \mathrm{O}_{4}$. Furthermore, we demonstrated the following synthesis: the precursor of $\mathrm{FeOOH}$ was employed as $\mathrm{FeOOH} / \mathrm{Mg}(\mathrm{OH})_{2}$, and the resultant complex phase was transformed into $\gamma-\mathrm{Fe}_{2} \mathrm{O}_{3}$ crystallites by dehydration. During this process, $\mathrm{Mg}(\mathrm{OH})_{2}$ species were dissolved in the reaction medium. Such a reaction takes place below the boiling point temperature of water. When the treating solution's temperature is lower than $70^{\circ} \mathrm{C}$, for example $40^{\circ} \mathrm{C}$, the reaction does not reach completion, leading to the formation of only a few $\mathrm{FeOOH}$ nanoparticles. Thus, the compositions of as-prepared samples were as follows: sample (1) contained $\mathrm{FeOOH}$ nanoparticles along with $\gamma-\mathrm{Fe}_{2} \mathrm{O}_{3}$-coated $\mathrm{FeCl}_{3} \cdot 6 \mathrm{H}_{2} \mathrm{O}\left(\gamma-\mathrm{Fe}_{2} \mathrm{O}_{3} / \mathrm{FeCl}_{3} \cdot 6 \mathrm{H}_{2} \mathrm{O}\right)$ nanoparticles, which correspond to the smaller and larger particles in sample (1) (See Figure 2). With a steady increase in temperature, this reaction progressed towards completion. At this stage, $\gamma-\mathrm{Fe}_{2} \mathrm{O}_{3}$ phase increased, but $\mathrm{FeOOH}$ phase decreased. Consequently, magnetization enhanced from samples (1) to (3).

When the temperature reached $70{ }^{\circ} \mathrm{C}$ and increased further, the as-prepared samples were obtained in the form of pure $\gamma-\mathrm{Fe}_{2} \mathrm{O}_{3} / \mathrm{FeCl}_{3} \cdot 6 \mathrm{H}_{2} \mathrm{O}$ nanoparticles. Since the as-prepared samples (3), and (5) contained $\gamma-\mathrm{Fe}_{2} \mathrm{O}_{3}$ and $\mathrm{FeCl}_{3} \cdot 6 \mathrm{H}_{2} \mathrm{O}$ phase, we infer that the magnetization of samples may be related to the ratio between the two phases [22]. It is noticed that though EDS measurements are usually not very sensitive to oxygen content, the ratio between $\mathrm{Fe}$ and $\mathrm{Cl}$ elements is independent on the oxygen content. So using the measured atomic percentages of $\mathrm{Fe}$ and $\mathrm{Cl}\left(\mathrm{a}_{\mathrm{Fe}}\right.$ and $\left.\mathrm{a}_{\mathrm{Cl}}\right)$, the molar percentages of $\mathrm{Fe}_{2} \mathrm{O}_{3}\left(\mathrm{y}_{\mathrm{Fe}}\right)$ and $\mathrm{FeCl}_{3} \cdot 6 \mathrm{H}_{2} \mathrm{O}$ compounds $\left(\mathrm{y}_{\mathrm{Cl}}\right)$ could be estimated by the following formulae:

$$
\begin{aligned}
& y_{\mathrm{Fe}}=\frac{\left(\mathrm{a}_{\mathrm{Fe}}-\mathrm{a}_{\mathrm{Cl}} / 3\right) / 2}{\left(\mathrm{a}_{\mathrm{Fe}}-\mathrm{a}_{\mathrm{al}} / 3\right) / 2+\mathrm{a}_{\mathrm{Cl}} / 3} . \\
& \mathrm{y}_{\mathrm{Cl}}=\frac{\mathrm{a}_{\mathrm{Cl}} / 3}{\left(\mathrm{a}_{\mathrm{Fe}}-\mathrm{a}_{\mathrm{Cl}} / 3\right) / 2+\mathrm{a}_{\mathrm{Cl}} / 3} .
\end{aligned}
$$

Here, $\mathrm{y}_{i}$ is the molar percentage of $i$ compound, in samples (3) and (5), and it can be obtained from the values of $\mathrm{a}_{\mathrm{Fe}}$ and $\mathrm{a}_{\mathrm{Cl}}$, which were previously measured by EDS and XPS analyses (see Table 2). The results of $\mathrm{y}_{i}$ are enlisted in Table 4 . As a consequence, the mass fraction percentage $\left(\mathrm{z}_{i}\right)$ and the volume fraction percentage $\left(\phi_{i}\right)$ of each compound in respective samples can be deduced from the following formulae:

$$
\mathrm{z}_{i}=\frac{\mathrm{y}_{i} \mathrm{~A}_{i}}{\sum \mathrm{y}_{i} \mathrm{~A}_{i}} \times 100
$$


and

$$
\phi_{i}=\frac{\mathrm{z}_{i} / \rho_{i}}{\sum \mathrm{z}_{i} / \rho_{i}} \times 100
$$

Table 4. Molar fraction percentages $\left(\mathrm{y}_{i}\right)$, mass fraction percentages $\left(\mathrm{z}_{i}\right)$, and volume fraction percentages $\left(\phi_{i}\right)$ determined by (a) EDS and (b) XPS.

\begin{tabular}{cccccccc}
\hline Samples & $\mathbf{y}_{\mathrm{Fe}}$ & $\mathbf{y}_{\mathrm{Cl}}$ & $\mathbf{z}_{\mathrm{Fe}}$ & $\mathbf{z}_{\mathrm{Cl}}$ & $\boldsymbol{\phi}_{\mathrm{Fe}}$ & $\boldsymbol{\phi}_{\mathrm{Cl}}$ & $\boldsymbol{\phi}_{\mathrm{Cl}} / \phi_{\mathrm{Fe}}$ \\
\hline $\mathbf{a}$ & & & & & & & \\
$\mathbf{( 3 )}$ & 97.14 & 2.85 & 95.27 & 4.73 & 88.41 & 11.59 & 0.13 \\
$\mathbf{( 5 )}$ & 97.80 & 2.20 & 96.33 & 3.67 & 90.88 & 9.12 & 0.10 \\
$\mathbf{b}$ & & & & & & & \\
$\mathbf{( 3 )}$ & 93.08 & 6.92 & 88.82 & 11.78 & 74.29 & 25.91 & 0.35 \\
$\mathbf{( 5 )}$ & 90.03 & 9.97 & 84.22 & 15.78 & 66.94 & 33.06 & 0.49 \\
\hline
\end{tabular}

Here, $\mathrm{A}_{i}$ and $\rho_{i}$ are the molar mass and the density of $i$ compound, respectively. Accordingly, $\mathrm{z}_{i}$ and $\phi_{i}$ values of each compound in samples (3) and (5) were calculated using the values of $\mathrm{y}_{i}$, the molar mass and density of $\gamma-\mathrm{Fe}_{2} \mathrm{O}_{3}$ and $\mathrm{FeCl}_{3} \cdot 6 \mathrm{H}_{2} \mathrm{O}$ (See Table 4). By referring to the data presented in Table 4, we infer that $\mathrm{FeCl}_{3} \cdot 6 \mathrm{H}_{2} \mathrm{O} / \mathrm{Fe}_{2} \mathrm{O}_{3}$ volume ratio $\left(\phi_{\mathrm{Cl}} / \phi_{\mathrm{Fe}}\right)$ obtained for each sample by XPS was much larger than that obtained by EDS. It is well-known that EDS information is obtained from signal depths that largely exceed the dimensions of nanoparticles, whereas XPS information is obtained from the surface to a depth of approximately $3 \lambda$ ( $\lambda=1.27 \mathrm{~nm}$ for Fe2P electrons) [31,32]. As Figure 6a shows, EDS results depict an average $\phi_{\mathrm{Cl}} / \phi_{\mathrm{Fe}}$ across the entire particle, whereas XPS results depict the ratio of nanoparticles' surface: $\mathrm{d}_{\mathrm{x}}$ is the depth measured by XPS; $\mathrm{d}_{\mathrm{Cl}}$ is the thickness of $\mathrm{FeCl}_{3} \cdot 6 \mathrm{H}_{2} \mathrm{O}$ surface layer and $\mathrm{d}_{\mathrm{Fe}}$ is $\mathrm{Fe}_{2} \mathrm{O}_{3}$ region probed. Thus, the difference in $\phi_{\mathrm{Cl}} / \phi_{\mathrm{Fe}}$ values computed from EDS and XPS results indicates that $\mathrm{FeCl}_{3} \cdot 6 \mathrm{H}_{2} \mathrm{O}$ is formed outside the $\mathrm{Fe}_{2} \mathrm{O}_{3}$ phase [33] in samples (3) and (5).

In this experiment, the measured results of XPS indicate that $\phi_{\mathrm{Cl}} / \phi_{\mathrm{Fe}}$ value of sample (5) is greater than that of sample (3). As shown in Figure 6a, the depth probed by XPS $\left(d_{x}\right)$ can be regarded as constant, so this difference in $\phi_{\mathrm{Cl}} / \phi_{\mathrm{Fe}}$ values indicates that $\mathrm{FeCl}_{3} \cdot 6 \mathrm{H}_{2} \mathrm{O}$ surface layer $\left(\mathrm{d}_{\mathrm{Cl}}\right)$ of sample (5) was thicker than that of sample (3). Therefore, $\mathrm{FeCl}_{3} \cdot 6 \mathrm{H}_{2} \mathrm{O}$ content in as-prepared samples increased with an increase in the temperature of the treating solution. However, the measured result obtained by EDS is opposite to that obtained by XPS. Therefore, the $\phi_{\mathrm{Cl}} / \phi_{\mathrm{Fe}}$ value obtained from the measured results of EDS is smaller for sample (5) than for sample (3). Thus, we conclude that $\mathrm{Fe}_{2} \mathrm{O}_{3}$ content in as-prepared samples would increase steadily with an increase in temperature. Let $V_{\mathrm{Fe}}^{(3)}$ and $V_{\mathrm{Fe}}^{(5)}$ represent $\mathrm{Fe}_{2} \mathrm{O}_{3}$ volume, while $V_{\mathrm{Cl}}^{(3)}$ and $V_{\mathrm{Cl}}^{(5)}$ represent $\mathrm{FeCl}_{3} \cdot 6 \mathrm{H}_{2} \mathrm{O}$ volume in samples (3) and (5), respectively. Thus, we deduce the following expressions:

$$
\begin{aligned}
& V_{F e}^{(5)}=V_{F e}^{(3)}+\Delta V_{F e} \\
& V_{C l}^{(5)}=V_{C l}^{(3)}+\Delta V_{C l}
\end{aligned}
$$

where $\Delta V_{\mathrm{Fe}}$ and $\Delta V_{\mathrm{Cl}}$ are incremental contents of $\mathrm{Fe}_{2} \mathrm{O}_{3}$ and $\mathrm{FeCl}_{3} \cdot 6 \mathrm{H}_{2} \mathrm{O}$ in samples (5) and (3), respectively. The results measured by EDS help us deduce the following expression: $\phi_{\mathrm{Fe}}^{(5)} / \phi_{\mathrm{Cl}}^{(5)}>\phi_{\mathrm{Fe}}^{(3)} / \phi_{\mathrm{Cl}}^{(3)}$, where $\phi_{\mathrm{Fe}}^{(5)}, \phi_{\mathrm{Cl}}^{(5)}$, and $\phi_{\mathrm{Fe}}^{(3)} \phi_{\mathrm{Cl}}^{(3)}$ are volume fraction percentages of $\mathrm{Fe}_{2} \mathrm{O}_{3}$ and $\mathrm{FeCl}_{3} \cdot 6 \mathrm{H}_{2} \mathrm{O}$ phases in samples (5) and (3), respectively. Using the expression $\phi_{F e} / \phi_{C l}=V_{F e} / V_{C l}$, we proved that $\Delta V_{F e} / \Delta V_{C l}>V_{F e}^{(3)} / V_{C l}^{(3)}\left(=\phi_{F e}^{(3)} / \phi_{C l}^{(3)}\right)$. Experimental results indicate that the value of $\phi_{F e}^{(3)} / \phi_{C l}^{(3)}$ is more than unity, so $\Delta V_{F e} / \Delta V_{C l}$ is more than unity. Thus, compared with sample (3), the incremental content of $\mathrm{Fe}_{2} \mathrm{O}_{3}\left(\Delta V_{F e}\right)$ is more than the incremental content of $\mathrm{FeCl}_{3} \cdot 6 \mathrm{H}_{2} \mathrm{O}\left(\Delta V_{C l}\right)$ for sample (5). Based on these results, we proposed the following process for the formation of nanoparticles:

First, $\mathrm{FeOOH}$ in the precursor was subjected to dehydration, which initially led to the seeds of $\gamma-\mathrm{Fe}_{2} \mathrm{O}_{3}$ crystals in the solution. This reaction was accelerated and completed due to the catalytic action 
of $\mathrm{FeCl}_{2}$ treating solution; the catalytic effect of this treating solution increased as its temperature was increased by heating. Simultaneously, some $\mathrm{Fe}^{2+}$ in the treating solution would undergo dismutation reaction as follows: $3 \mathrm{Fe}^{2+} \rightarrow 2 \mathrm{Fe}^{3+}+\mathrm{Fe}^{0}[34,35]$. Then, the resultant $\mathrm{Fe}^{0}$ would be oxygenated to form iron oxide in the presence of atmospheric oxygen: $4 \mathrm{Fe}^{0}+3 \mathrm{O}_{2} \rightarrow 2 \mathrm{Fe}_{2} \mathrm{O}_{3}$. Thus, an epitaxial $\mathrm{Fe}_{2} \mathrm{O}_{3}$ layer was built on initial crystallites, and $\mathrm{FeCl}_{3} \cdot 6 \mathrm{H}_{2} \mathrm{O}$ was adsorbed onto an epitaxial layer during the precipitation process. Consequently, we synthesized $\gamma-\mathrm{Fe}_{2} \mathrm{O}_{3}$ based nanoparticles coated with $\mathrm{FeCl}_{3} \cdot 6 \mathrm{H}_{2} \mathrm{O}$. Such a chemical reaction involving the steps of dismutation and oxygenation can be written as follows:

$$
12 \mathrm{Fecl}_{2}+3 \mathrm{O}_{2} \stackrel{\Delta}{\rightarrow} 8 \mathrm{Fecl}_{3}+2 \mathrm{Fe}_{2} \mathrm{O}_{3}
$$

A schematic model of particle structure is shown in Figure 6b. Obviously, this reaction (involving dismutation and oxygenation) would be enhanced by increasing the temperature of the treating solution. Consequently, both $\mathrm{Fe}_{2} \mathrm{O}_{3}$ and $\mathrm{FeCl}_{3} \cdot 6 \mathrm{H}_{2} \mathrm{O}$ contents in as-prepared samples increased with temperature.

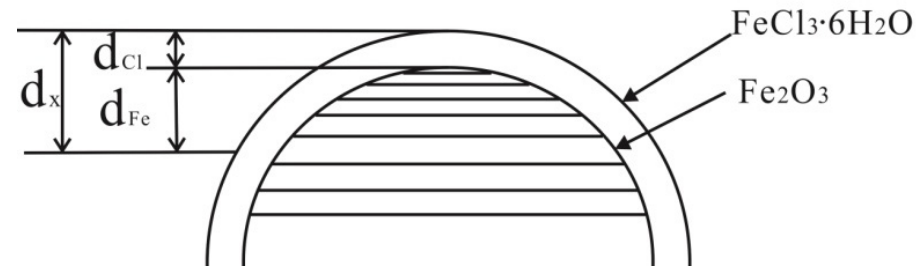

(a)

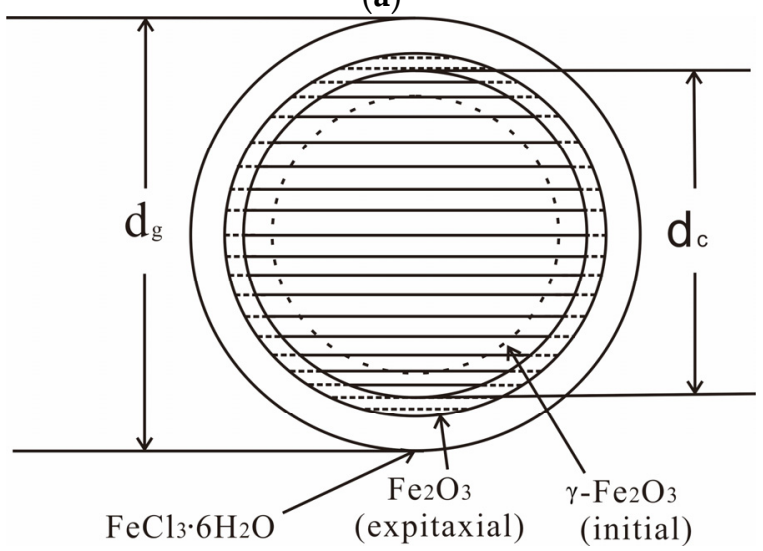

(b)

Figure 6. Schematic diagram of the XPS measurement's region, $d_{x}$, which is the depth detected by XPS (a). Schematic model of nanoparticle structure in samples (3) and (5) (b).

For the system of particles containing many phases, magnetization can be described as follows: $\mathrm{M}=\sigma\langle\rho\rangle$, where $\langle\rho\rangle$ is the average density of every sample, and it can be obtained as follows:

$$
<\rho>=\frac{\sum \phi_{i} \rho_{i}}{\sum \phi_{i}} .
$$

Herein, $\phi_{i}$ and $\rho_{i}$ are volume fraction percentage and density of $i$ phase, respectively. Thus, based on $\phi_{\mathrm{Fe}}$ and $\phi_{\mathrm{Cl}}$ values measured by EDS and the densities of $\gamma-\mathrm{Fe}_{2} \mathrm{O}_{3}$ and $\mathrm{FeCl}_{3} \cdot 6 \mathrm{H}_{2} \mathrm{O}, 4.90 \times 10^{3}$ and $1.844 \times 10^{3} \mathrm{~kg} / \mathrm{m}^{3}$, respectively, the $\rho$ value was calculated. It was found to be $4.55 \times 10^{3}$ and $4.62 \times 10^{3} \mathrm{~kg} / \mathrm{m}^{3}$ for samples (3) and (5), respectively. As a consequence, the saturation magnetization $\left(\mathrm{M}_{\mathrm{s}}\right)$ can be obtained from $\sigma_{\mathrm{s}}$ and $\rho$, and it was computed to be 320.82 and $307.74 \mathrm{kA} / \mathrm{m}$ for samples (3) and (5), respectively. In addition, the magnetization can be determined as follows: $M=\left(\phi_{F e} M_{F e}+\phi_{C l} M_{C l}\right) / 100$, where $\mathrm{M}_{\mathrm{Fe}}$ and $\mathrm{M}_{\mathrm{Cl}}$ are the magnetization of $\gamma-\mathrm{Fe}_{2} \mathrm{O}_{3}$ and $\mathrm{FeCl}_{3} \cdot 6 \mathrm{H}_{2} \mathrm{O}$ 
compounds, respectively. According to the definition of volume fraction percentage, $\phi_{\mathrm{Fe}}+\phi_{\mathrm{Cl}}=100$, $\mathrm{M}$ can be written as follows:

$$
M=\frac{1}{1+\phi_{C l} / \phi_{F e}}\left(M_{F e}-M_{C l}\right)+M_{C l}
$$

$M_{F e}$ and $M_{C l}$ are regarded as contents. Thus, using the relations $M_{F e}>M_{C l}$ and $\phi_{\mathrm{Fe}}>>\phi_{\mathrm{Cl}}$, the Formula (7) can be written simply as follows:

$$
M=\frac{M_{F e}}{1+\phi_{C l} / \phi_{F e}} .
$$

From Formula (8), we conclude that saturation magnetization $\left(\mathrm{M}_{\mathrm{S}}\right)$ is inversely related to $\phi_{\mathrm{Cl}} / \phi_{\mathrm{Fe}}$. Therefore, the smaller the value of $\phi_{\mathrm{Cl}} / \phi_{\mathrm{Fe}}$, the stronger would be $\mathrm{M}_{\mathrm{s}}$. However, experimental results appear to be contradictory because $\mathrm{M}_{\mathrm{s}}$ is lower for sample (5) than for sample (3), despite the fact that the $\phi_{\mathrm{Cl}} / \phi_{\mathrm{Fe}}$ value of the former is smaller than the latter (see Table 4). This paradox means that the apparent magnetization of as-prepared sample could be not only related to chemical compounds but also to their effective magnetic compounds. We substantiate our claim in the following paragraph.

Surface magnetic properties become extremely important with a decrease in particle size, since a decrease in particle size leads to an increase in surface-to-volume ratio. The properties depend on the surface microstructure and the surrounding, e.g., generally because of variation in the local and exchange fields [34]. In magnetic nanoparticles, crystal symmetry breaking at the surface results in surface anisotropy. This phenomenon is more pronounced in ferrimagnets [36]. Many ramifications are associated with breaking of crystal symmetry at the surface of crystallites. One of the most important developments would be the occurrence of spin disorder in the surface layer [37,38]. With a thickness of 0.3-1.0 nm, the disordered surface layer is similar to a magnetic "dead layer" [29]. Experimental results indicate that the grain size $\left(\mathrm{d}_{\mathrm{c}}\right)$ of both the samples (5) and (3) were almost the same when we compared the measured results obtained by XRD; however, the physical size $\left(\mathrm{d}_{\mathrm{g}}\right)$ measured by TEM is greater for the former (sample 5) than for the latter (sample 3), while the $\mathrm{Fe}_{2} \mathrm{O}_{3}$ content $\left(\phi_{\mathrm{Fe}}\right)$ measured by EDS is greater for the former than for the latter. Based on these results, we infer that the epitaxial $\mathrm{Fe}_{2} \mathrm{O}_{3}$ layer, which forms on the initial seed crystallites, may have a disordered surface layer due to the breaking of crystal symmetry. This expanse of the disordered layer is similar to the amorphous component and it does not influence XRD measurement because only the crystalline phase is detected with XRD [29]. The thickness of the disordered layer increases as the temperature of the treating solution is increased. Such a disordered layer seems to be magnetically silent, and it does not stimulate the apparent magnetization in any way [38]. The contents of both $\mathrm{FeCl}_{3} \cdot 6 \mathrm{H}_{2} \mathrm{O}$ and epitaxial $\mathrm{Fe}_{2} \mathrm{O}_{3}$ in sample (5) are more than those in sample (3); however, the content of $\gamma-\mathrm{Fe}_{2} \mathrm{O}_{3}$ crystal, that is, the effective magnetic component is almost the same in samples (5) and (3), so the magnetization of sample (5) is weaker than that of sample (3). Accordingly, it can summarized that as the treating solution's temperature was increased from 70 to $90{ }^{\circ} \mathrm{C}$, the content of both $\mathrm{FeCl}_{3} \cdot 6 \mathrm{H}_{2} \mathrm{O}$ and the disordered $\mathrm{Fe}_{2} \mathrm{O}_{3}$ increased so that the magnetization behavior of as-prepared samples became weak with a steady increase in temperature.

The zero-field cooled (ZFC) and field-cooled (FC) measurements for magnetic behaviors can reveal the super paramagnetic behavior of a sample. This could be interesting to clarify possible interactions between the different magnetic phases in the sample [39], and will be performed in further work. Mössbauer spectroscopy may be used to distinguish $\gamma-\mathrm{Fe}_{2} \mathrm{O}_{3}$ from $\mathrm{Fe}_{3} \mathrm{O}_{4}$, since $\gamma-\mathrm{Fe}_{2} \mathrm{O}_{3}$ and $\mathrm{Fe}_{3} \mathrm{O}_{4}$ give quite a different spectrum, both above and below the Verwey transition [40]. It will be considered in further works that using Mössbauer spectroscopy can determine the maghemite phase in the nanoparticles. 


\section{Conclusions}

Using $\mathrm{FeOOH} / \mathrm{Mg}(\mathrm{OH})_{2}$ as a precursor, we prepared $\gamma-\mathrm{Fe}_{2} \mathrm{O}_{3}$ based magnetic nanoparticles in $\mathrm{FeCl}_{2}$ solution. In this chemical reaction, we found that the magnetization of as-prepared products had a non-monotonical variation with an increase in the temperature of treated solution $\left(\mathrm{FeCl}_{2}\right)$. Experimental results indicate that the magnetization behavior of the as-prepared samples is not only related to the chemical compounds present in the particles, but it also governs the formation of nanoparticles and their effectively magnetic compounds. When the treating solution's temperature was below $70^{\circ} \mathrm{C}$, for example $40-60^{\circ} \mathrm{C}$, the hydration reaction involving $\mathrm{FeOOH}$ species from the precursor does not reach completion. However, the $\gamma-\mathrm{Fe}_{2} \mathrm{O}_{3}$ crystallite core is formed initially in this reaction. As a result, the as-prepared samples contained $\mathrm{FeOOH}$ nanoparticles along with $\gamma-\mathrm{Fe}_{2} \mathrm{O}_{3} / \mathrm{FeCl}_{3} \cdot 6 \mathrm{H}_{2} \mathrm{O}$ nanoparticles, and their magnetization levels were weaker. When the temperature of the treated $\mathrm{FeCl}_{2}$ solution was increased from 70 to $90{ }^{\circ} \mathrm{C}$, we could obtain as-prepared samples containing only $\gamma-\mathrm{Fe}_{2} \mathrm{O}_{3} / \mathrm{FeCl}_{3} \cdot 6 \mathrm{H}_{2} \mathrm{O}$ nanoparticles. Both $\mathrm{Fe}_{2} \mathrm{O}_{3}$ and $\mathrm{FeCl}_{3} \cdot 6 \mathrm{H}_{2} \mathrm{O}$ contents increased completely with an increase in temperature. Furthermore, we infer that the $\mathrm{FeCl}_{2}$ treating solution, which has a catalytic effect on the dehydration of $\mathrm{FeOOH}$ and its subsequent transformation into $\gamma-\mathrm{Fe}_{2} \mathrm{O}_{3}$ seed crystals, could appear as a two-step reaction involving dismutation and oxygenation; the reaction led to the formation of $\mathrm{FeCl}_{3}$ and $\mathrm{Fe}_{2} \mathrm{O}_{3}$ as products of dismutation and oxygenation, respectively. Moreover, the contents of both $\mathrm{FeCl}_{3}$ and $\mathrm{Fe}_{2} \mathrm{O}_{3}$ would increase with an increase in temperature. In this synthesis reaction, $\mathrm{Fe}_{2} \mathrm{O}_{3}$ grows epitaxially on the initial seed crystals of $\gamma-\mathrm{Fe}_{2} \mathrm{O}_{3}$, whereas $\mathrm{FeCl}_{3}$ is absorbed to form $\mathrm{FeCl}_{3} \cdot 6 \mathrm{H}_{2} \mathrm{O}$ on the outermost layer of the particles. This epitaxial $\mathrm{Fe}_{2} \mathrm{O}_{3}$ could have a $\gamma-\mathrm{Fe}_{2} \mathrm{O}_{3}$ phase layer and disordered surface layer. The disordered surface has the breaking of crystal symmetry, so it seems to be a magnetically silent layer. As a result, it does not have any role in the apparent magnetization of nanoparticles. As the treating solution's temperature was increased tom 70 to $90{ }^{\circ} \mathrm{C}$, the content of both the products, namely, $\mathrm{FeCl}_{3} \cdot 6 \mathrm{H}_{2} \mathrm{O}$ and the disordered $\mathrm{Fe}_{2} \mathrm{O}_{3}$ increased sharply. Consequently, the magnetization behavior of as-prepared samples became weak with a steady increase in temperature.

Acknowledgments: The financial support for this work was provided by the following institutions: the Fundament Research Fund for the Central University of China (grant number XDJK2017D139), and National Natural Science Foundation of China (grant number 11274257), the Natural Science Foundation of Chongqing (grant number CSTC 2011jeyjA40029).

Author Contributions: T.Z. carried out preparation of samples and analysis of the characterization results, and drafted the manuscript. X.M. participated in the sequence alignment and help to draft the manuscript. Z.H. help to carry out characteristical studies. Y.L. and X.L. carried out the measurements of both VSM and XRD. D.L. participated in the design of the study. J.L. and X.Q. conceived of the study, and participated in the design and coordination. All authors read and approved the final manuscript.

Conflicts of Interest: The authors declare that they have no conflicts of interest.

\section{References}

1. Mathew, D.S.; Juang, R.-S. An overview of the structure and magnetism of spinel ferrite nanoparticles and their synthesis in microemulsions. Chem. Eng. J. 2007, 129, 51-65. [CrossRef]

2. Willard, M.A.; Kurihara, L.K.; Carpenter, E.E.; Calvin, S.; Harris, V.G. Chemically Prepared Magnetic Nanoparticles. Int. Mater. Rev. 2004, 36, 125-170. [CrossRef]

3. Talapin, D.V.; Lee, J.-S.; Kovalenko, M.V.; Shevchenko, E.V. Prospects of colloidal nanocrystals for electronic and optoelectronic applications. Chem. Rev. 2010, 110, 389-458. [CrossRef] [PubMed]

4. Kim, B.H.; Hackett, M.J.; Pcok, J.; Hyeon, A.T. Synthesis, Characterization, and Application of Ultrasmall Nanoparticles. Chem. Mater. 2014, 26, 59-71. [CrossRef]

5. Alqasem, B.; Yahya, N.; Qureshi, S.; Irfan, M.; Rehman, Z.U.; Soleimani, H. The enhancement of the magnetic properties of $\alpha-\mathrm{Fe}_{2} \mathrm{O}_{3}$ nanocatalyst using an external magnetic field for the production of green ammonia. Mater. Sci. Eng. B 2017, 217, 49-62. [CrossRef]

6. Cushing, B.L.; Kolenichenko, V.L.; O'conor, C.J. Recent Advances in the Liquid-Phase Syntheses of Inorganic Nanoparticles. Chem. Rev. 2004, 104, 3893-3946. [CrossRef] [PubMed] 
7. Lee, S.-Y.; Harris, M.T. Surface modification of magnetic nanoparticles capped by oleic acids: Characterization and colloidal stability in polar solvents. J. Colloid Interface Sci. 2006, 293, 401-408. [CrossRef] [PubMed]

8. Restrepo, J.; Labaye, Y.; Greneche, J.M. Surface anisotropy in maghemite nanoparticles. Physica B 2006, 384, 221-223. [CrossRef]

9. Laurent, S.; Forge, D.; Port, M.; Roch, A.; Elst, L.V.; Muller, R.N. Magnetic Iron Oxide Nanoparticles: Synthesis, Stabilization, Vectorization, Physicochemical Characterizations, and Biological Applications. Chem. Rev. 2008, 108, 2064-2110. [CrossRef] [PubMed]

10. Yu, S.; Chow, C.M. Carboxyl group $\left(-\mathrm{CO}_{2} \mathrm{H}\right)$ functionalized ferrimagnetic iron oxide nanoparticles for potential bio-applications. J. Mater. Chem. 2004, 14, 2781-2786. [CrossRef]

11. Szabó, D.V.; Vollath, D. Nanocomposites from coated nanopparticles. Adv. Mater. 1999, 11, $1313-1316$. [CrossRef]

12. Narasimhan, B.R.V.; Prabhakar, S.; Manohar, P.; Granam, F.D. Synthesis of gamma ferric oxide by direct thermal decomposition of ferrous carbonate. Mater. Lett. 2002, 52, 295-300. [CrossRef]

13. Hyeon, T.; Lee, S.S.; Park, J.; Chung, Y.; Na, H.B. Synthesis of highly crystalline and monodisperse maghemite nanocrystallites without a size-selection process. J. Am. Chem. Soc. 2001, 123, 12798-12801. [CrossRef] [PubMed]

14. Shafi, K.V.P.M.; Ulman, A.; Yan, X.; Yang, N.L.; Estournès, C.; White, H.; Rafailovich, M. Sonochemical Synthesis of Functionalized Amorphous Iron Oxide Nanoparticles. Langmuir 2001, 17, 5093-5097. [CrossRef]

15. Nakanishi, T.; Iida, H.; Osaka, T. Preparation of Iron Oxide Nanoparticles via Successive Reduction-Oxidation in Reverse Micelles. Chem. Lett. 2003, 32, 1166-1167. [CrossRef]

16. Sreeja, V.; Joy, P.A. Microwave-hydrothermal synthesis of $\gamma-\mathrm{Fe}_{2} \mathrm{O}_{3}$ nanoparticles and their magnetic properties. Mater. Res. Bull. 2007, 42, 1570-1576. [CrossRef]

17. Rouanet, A.; Solmon, H.; Pichelin, G.; Roucau, C.; Sibieude, F.; Monty, C. Synthesis by vaporization-condensation and characterization of $\gamma-\mathrm{Fe}_{2} \mathrm{O}_{3}, \mathrm{In}_{2} \mathrm{O}_{3}, \mathrm{SnO}_{2}, \mathrm{ZnO}$ and $\mathrm{Zr}_{1-\mathrm{x}} \mathrm{Y}_{\mathrm{x}} \mathrm{O}_{2}$-nanophases. Nanostruct. Mater. 1995, 6, 283-286. [CrossRef]

18. Casas, L.; Roig, A.; Molins, E.; Grenèche, J.M.; Asenjo, J.; Tejata, J. Iron oxide nanoparticles hosted in silica aerogels. Appl. Phys. A 2002, 74, 591-597. [CrossRef]

19. Maeda, Y.; Manabe, T.; Nagai, K.; Yoshimura, F.; Hirono, S. High Coercive SiOx- adsorbed $\gamma-\mathrm{Fe}_{2} \mathrm{O}_{3}$ particles. In Ferrites; Proc. Inter. Con. Jpn.: Tokyo, Japan, 1982; pp. 541-544.

20. Hsu, J.H.; Chang, C.R.; Kuo, P.C.; Huang, J.H. Annealing effect on magnetic properties of Si-modified $\gamma-\mathrm{Fe}_{2} \mathrm{O}_{3}$ particles. J. Magn. Magn. Mater. 1990, 89, 167-172. [CrossRef]

21. Wen, B.C.; Li, J.; Lin, Y.Q.; Liu, X.D.; Fu, J.; Miao, H.; Zhang, Q.M. A novel preparation method for $\gamma-\mathrm{Fe}_{2} \mathrm{O}_{3}$ nanoparticles and their characterization. Mater. Chem. Phys. 2011, 128, 35-38. [CrossRef]

22. Fu, J.; Lin, L.H.; Li, J. A Novel Preparation Method for Magnetic Nanoparticles and Their Characterization; FMTIF: Chongqing, China, 2011; pp. 46-50.

23. Chen, Y.S.; Chen, Q.; Mao, H.; Zhang, T.; Qiu, X.Y.; Lin, Y.Q.; Li, J. Preparation of magnetic nanoparticles via chemically induced transition: Dependence of components and magnetization on the concentration of treating solution used. Nanomater. Nanotechnol. 2017, 7, 1-9. [CrossRef]

24. Arulmurugan, R.; Vaidyanathan, G.; Sendhilnathan, S.; Jeyadevan, B. Co-Zn ferrite nanoparticles for ferrofluid preparation: Study on magnetic properties. Physica B 2005, 363, 225-231. [CrossRef]

25. Grangvist, C.G.; Bhrman, R.A. Ultrafine metal particles. J. Appl. Phys. 1976, 47, 2200-2219. [CrossRef]

26. Sato, T.; Iijima, T.; Seki, M.; Inagaki, N. Magnetic properties of ultrafine ferrite particles. J. Magn. Magn. Mater. 1987, 65, 252-256. [CrossRef]

27. Blanco-Mantecón, M.; O'Grady, K. Interaction and size effects in magnetic nanoparticles. J. Magn. Magn. Mater. 2006, 296, 124-133. [CrossRef]

28. Cong, C.J.; Hong, J.H.; Liu, Q.Y.; Liao, L.; Zhang, K.L. Synthesis, Structure and ferromagnetic properties of Ni-dopeed ZnO nanoparticles. Solid State Commun. 2006, 138, 511-515. [CrossRef]

29. Frison, R.; Cernuto, G.; Cervellino, A.; Zaharko, O.; Colonna, G.M.; Guagliardi, A.; Masciocchi, N. Magnetite-Maghemite Nanoparticles in the 5-15 nm Range: Correlating the Core-Shell Composition and the Surface Structure to the Magnetic Properties. A Total Scattering Study. Chem. Mater. 2013, 25, 4820-4827. [CrossRef]

30. Li, J.; Qiu, X.Y.; Lin, Y.Q.; Liu, X.D.; Gao, R.L.; Wang, A.R. A study of modified $\mathrm{Fe}_{3} \mathrm{O}_{4}$ nanoparticles for the synthesis of ionic ferrofluids. Appl. Surf. Sci. 2010, 256, 6977-6981. [CrossRef] 
31. Srnová-Sloufová, I.; Vlcková, B.; Bastl, Z.; Hasslett, T.L. Bimetallic (Ag)Au nanoparticles prepared by the seed growth method: Two-dimensional assembling, characterization by energy dispersive X-ray analysis, X-ray photoelectron spectroscopy, and surface enhanced Raman spectroscopy, and proposed mechanism of growth. Langmuir 2004, 20, 3407-3415. [PubMed]

32. Tanuma, S.; Powell, C.J.; Penn, D.R. Calculations of electron inelastic mean free paths. II. Data for 27 elements over the 50-2000 eV range. Surf. Interface Anal. 1991, 17, 911-926. [CrossRef]

33. Li, J.; Lin, Y.; Liu, X.; Zhang, Q.; Miao, H.; Zhang, T.; Wen, B. The study of transition on $\mathrm{NiFe}_{2} \mathrm{O}_{4}$ nanoparticles prepared by co-precipitation/calcination. Phase Trans. 2011, 84, 49-57. [CrossRef]

34. Zhang, Q.M.; Li, J.; Mao, H.; Fu, J. Preparation of $\gamma-\mathrm{Fe}_{2} \mathrm{O}_{3} / \mathrm{Ni}_{2} \mathrm{O}_{3} / \mathrm{FeCl}_{3}\left(\mathrm{FeCl}_{2}\right)$ composite nanoparticles by hydrothermal process useful for ferrofluids. Smart Mater. Res. 2011, 2011. [CrossRef]

35. Larcher, D.; Bonnin, D.; Cortes, R.; Rivals, I.; Personnaz, L.; Tarascon, J.-M. Combined XRD, EXAFS, and Mössbauer Studies of the Reduction by Lithium of $\alpha-\mathrm{Fe}_{2} \mathrm{O}_{3}$ with Various Particle Size. J. Elecreochem. Soc. 2003, 150, A1643-A1650. [CrossRef]

36. Tronc, E.; Ezzir, A.; Cherkaoui, R.; Chanéac, C.; Noguès, M.; Kachkachi, H.; Fiorani, D.; Testa, A.M.; Grenèche, J.M.; Jolivet, J.P. Surface-related properties of $\gamma-\mathrm{Fe}_{2} \mathrm{O}_{3}$ nanoparticles. J. Magn. Magn. Mater. 2000, 221, 63-79. [CrossRef]

37. Kachkachi, H.; Ezzir, A.; Noguès, M.; Tronc, E. Surface effects in nanoparticles: Application to maghemite. Eur. Phys. J. B 2000, 14, 681-689. [CrossRef]

38. Kodama, R.H.; Berkowitz, A.E.; McNiff, E.J.; Foner, S. Surface Spin Disorder in $\mathrm{NiFe}_{2} \mathrm{O}_{4}$ Nanoparticles. Phys. Rev. Lett. 1996, 7, 394-397. [CrossRef] [PubMed]

39. Salazar-Alvarez, G.; Sort, J.; Uheida, A.; Muhammed, M.; Suriñach, S.; Baró, M.D.; Nogués, J. Reversible post-synthesis tuning of the superparamagnetic blocking temperature of $\gamma-\mathrm{Fe}_{2} \mathrm{O}_{3}$ nanoparticles by adsorption and desorption of Co(II) ions. J. Mater. Chem. 2007, 17, 322-328. [CrossRef]

40. Coey, J.M.D.; Khalafalla, D. Superparamagnetic $\gamma-\mathrm{Fe}_{2} \mathrm{O}_{3}$. Phys. Status Solidi (A) 1972, 11, 229-241. [CrossRef]

(C) 2017 by the authors. Licensee MDPI, Basel, Switzerland. This article is an open access article distributed under the terms and conditions of the Creative Commons Attribution (CC BY) license (http:/ / creativecommons.org/licenses/by/4.0/). 